\title{
Ensayos clínicos sobre Plasma convaleciente en COVID-19 realizados en países de la región
}

\section{Clinical trials on Convalescent Plasma in COVID. 19 performed in regional countries}

Mercy E. Fernández-Moya ${ }^{1}$, Claudia E. Pacherres-Ochoa ${ }^{1}$, Denis M. Pacheco-Chinchay', Joshuan J. Barboza ${ }^{1,2}$

\begin{abstract}
Señor editor,
La terapia con plasma convaleciente ha sido utilizada para el tratamiento de pacientes con infecciones virales como la influenza AH1N1 o en Ébola. Actualmente, el plasma convaleciente se ha propuesto como una alternativa terapéutica y profiláctica para pacientes con COVID-19 $19^{(1)}$.
\end{abstract}

El anticuerpo anti-SARS-COV-2 contenido en el plasma, obtenido de los individuos recuperados que habían confirmado la presencia de COVID-19, se ha empezado a recoger mediante dispositivos de aféresis y se ha almacenado en bancos de sangre en algunos países, entre ellos muchos de la región ${ }^{(2)}$.

Sin embargo, como investigadores nos cuestionamos sobre las condiciones, características y la relevancia clínica de los estudios realizados en Latinoamérica. De esta manera, realizamos una búsqueda sistemática en las diferentes bases de datos de registros de protocolos de ensayos clínicos, tales como "NIH Clinical Trial: https://clinicaltrials.gov", "WHO Clinical trial registry platform: https://apps.who.int/trialsearch/", "Registro brasilero de ensayos clínicos: http://www.ensaiosclinicos.gov.br". Se utilizaron tesauros y palabras controladas como "COVID-19" OR "COVID19", y "Convalescent Plasma". Luego de la búsqueda, de forma independiente entre 3 de los autores se realizó la selección de aquellos protocolos de estudio realizados en América del Sur, que evaluaron la utilización profiláctica o terapéutica del plasma convaleciente en pacientes con COVID-19. Finalmente, se realizó la extracción de forma independiente de los datos preliminares de nuestros resultados, que forman parte de nuestra revisión sistemática, cuyo protocolo ha sido enviado para su registro en la plataforma PROSPERO. Para esta presentación preliminar, se ha 1. Escuela de Medicina, Universidad Señor de Sipán, Chiclayo, Perú
2. Tau-Relaped Group. omitido la realización del análisis de riesgo de sesgo, puesto que se presentará únicamente con los estudios originales concluidos de cada estudio, que se publicarán de forma extensa posteriormente.

Luego de la búsqueda, se encontró 166 registros de protocolos de ensayos clínicos. Se excluyeron todos los registros de países fuera de América del Sur, y se incluyeron en total 25 registros de protocolos. Se extrajo la información de cada estudio, cuyos datos se observan en la Tabla 1.

En síntesis, se observan 8 protocolos realizados en México, 4 protocolos en Brasil, 4 estudios en Argentina, 7 protocolos en Colombia y sólo un registro en Chile y un estudio en Perú. De los 25 protocolos, sólo el $32 \%(n=8)$ están en fase 3. La mayoría de estudios describió como intervención la infusión entre 200 a $600 \mathrm{ml}$ de plasma convaleciente entre 24 y 48 horas, y como control al cuidado de soporte o estándar.

El objetivo de esta comunicación es poder crear un puente permanente y contínuo de revisión sistemática de los ensayos clínicos realizados sobre el tratamiento con plasma convaleciente en países de la región, y de esa manera informar acerca de la eficacia y de la relevancia clínica para los pacientes con COVID-19.

Conflictos de interés: Los autores niegan conflictos de interés.

Financiamiento: Autofinanciado.

\section{REFERENCIAS BIBLIOGRÁFICAS}

1. Salazar E, Perez KK, Ashraf M, Chen J, Castillo B, Christensen PA, et al. Treatment of COVID-19 Patients with Convalescent Plasma in Houston, Texas. medRxiv. 2020.

2. Yigenoglu TN, Hacibekiroglu T, Berber I, Dal MS, 
Basturk A, Namdaroglu S, et al. Convalescent plasma therapy in patients with COVID-19. J Clin Apher. 2020;35(4):367-73.

\section{Correspondencia}

Joshuan Jordano Barboza Meca.
Teléfono: 992108520

Correo: jbarbozameca@relaped.com

Revisión de pares

Recibido: 09/11/2020

Aceptado: 15/12/2020

Tabla 1. Características de los registros de protocolos de ensayos clínicos incluidos

\begin{tabular}{|c|c|c|c|c|c|c|c|}
\hline Registro & Lugar/Sede & Título & $\begin{array}{l}\text { Fase del } \\
\text { ensayo }\end{array}$ & Estado & $\begin{array}{c}\text { Características de los } \\
\text { pacientes }\end{array}$ & Intervención/Control & Desenlace primario \\
\hline NCT04547660 & $\begin{array}{l}\text { Hospital de } \\
\text { Clínicas de Porto } \\
\text { Alegre, Porto } \\
\text { Alegre, Rio Grande } \\
\text { Do Sul, Brazil }\end{array}$ & $\begin{array}{l}\text { Convalescent Plasma for } \\
\text { Severe COVID-19 } \\
\text { Patients }\end{array}$ & Fase 3 & Reclutamiento & $\begin{array}{l}\text { Pacientes } \\
\text { hospitalizados con } \\
\text { diagnóstico de } \\
\text { SARS-CoV-2 }\end{array}$ & $\begin{array}{l}\text { Transfusión de } 2 \text { alícuotas de } 300 \mathrm{ml} \text { de } \\
\text { plasma convaleciente congelado, con } 2 \\
\text { días de diferencia, descongelado a } 37 \\
\text { grados antes de la infusión/ } \\
\text { Tratamiento de soporte }\end{array}$ & $\begin{array}{l}\text { Mejora clínica a los } \\
28 \text { días }\end{array}$ \\
\hline NCT04542967 & $\begin{array}{l}\text { Hospital Central } \\
\text { Militar, Mexico } \\
\text { City, Mexico }\end{array}$ & $\begin{array}{l}\text { Study on the Safety and } \\
\text { Efficacy of Convalescent } \\
\text { Plasma in Patients with } \\
\text { Severe COVID-19 Disease }\end{array}$ & Fase 2 & Reclutamiento & $\begin{array}{l}\text { Pacientes } \\
\text { hospitalizados, con } \\
\text { enfermedad grave } \\
\text { por COVID-19 }\end{array}$ & $\begin{array}{l}\text { Unidad de } 200 \mathrm{ml} \text { de infusión } \\
\text { intravenosa de plasma convaleciente } \\
\text { cada } 24 \text { horas para dos } \\
\text { dosis/Tratamiento estándar }\end{array}$ & $\begin{array}{l}\text { Progresión de la } \\
\text { enfermedad, efectos } \\
\text { secundarios, } \\
\text { mortalidad a los } 30 \\
\text { días }\end{array}$ \\
\hline NCT04535063 & $\begin{array}{l}\text { Centro de } \\
\text { Educación Médica } \\
\text { e Investigaciones } \\
\text { Clínicas, Buenos } \\
\text { Aires, Argentina }\end{array}$ & $\begin{array}{l}\text { Convalescent Plasma as } \\
\text { Potential Therapy for } \\
\text { Severe COVID-19 } \\
\text { Pneumonia }\end{array}$ & Fase 3 & Reclutamiento & $\begin{array}{l}\text { Pacientes con } \\
\text { neumonía severa } \\
\text { COVID-19. } \\
\text { Pacientes } \\
\text { hospitalizados }\end{array}$ & $\begin{array}{l}\text { Infusión intravenosa de } 300-600 \mathrm{~mL} \text { de } \\
\text { plasma convaleciente con un título de } \\
\text { anticuerpos superior a } 3 \text { según el } \\
\text { inmunoensayo de micropartículas } \\
\text { quimioluminiscentes/No control }\end{array}$ & $\begin{array}{l}\text { Supervivencia a los } \\
28 \text { días }\end{array}$ \\
\hline NCT04497324 & $\begin{array}{l}\text { Hospital Nacional } \\
\text { Hipolito Unanue, } \\
\text { Lima, Peru }\end{array}$ & $\begin{array}{l}\text { PERUCONPLASMA: } \\
\text { Evaluating the Use of } \\
\text { Convalescent Plasma as } \\
\text { Management of COVID- } \\
19\end{array}$ & Fase 2 & $\begin{array}{l}\text { Aún no se ha } \\
\text { reclutado }\end{array}$ & $\begin{array}{l}\text { Pacientes } \\
\text { hospitalizados con } \\
\text { COVID-19 }\end{array}$ & $\begin{array}{l}\text { Administración de } 1 \text { a } 2 \text { unidades de } \\
\text { plasma para convalecientes ( } 200 \mathrm{ml} \text { a } \\
250 \mathrm{ml} \text {, cada una), en un plazo de } 48 \\
\text { horas, además de los cuidados } \\
\text { estándar/Cuidado estándar }\end{array}$ & $\begin{array}{l}\text { Eventos adversos } \\
\text { graves relacionados } \\
\text { con la transfusión a } \\
14 \text { días }\end{array}$ \\
\hline NCT04480632 & $\begin{array}{l}\text { Hospital } \\
\text { Internacional de } \\
\text { Colombia, } \\
\text { Piedecuesta, } \\
\text { Santander, } \\
\text { Colombia }\end{array}$ & $\begin{array}{l}\text { Therapeutic } \\
\text { Plasmapheresis in } \\
\text { Critically III Adult } \\
\text { Patients With COVID-19 } \\
\text { Confirmed Diagnosis }\end{array}$ & Fase 2 & $\begin{array}{l}\text { Aún no se ha } \\
\text { reclutado }\end{array}$ & $\begin{array}{l}\text { Pacientes } \\
\text { hospitalizados } \\
\text { críticos con COVID- } \\
19\end{array}$ & $\begin{array}{l}\text { Se administrará una dosis de } 500 \mathrm{ml} \text { de } \\
\text { plasma convaleciente (de un solo } \\
\text { donante o dos unidades de } 250 \mathrm{ml} \text { de } \\
\text { una o dos donaciones) recolectada por } \\
\text { aféresis. / Tratamiento estándar }\end{array}$ & $\begin{array}{l}\text { Mortalidad } \\
\text { intrahospitalaria a } \\
\text { los } 30 \text { días }\end{array}$ \\
\hline NCT04479163 & $\begin{array}{l}\text { Hospital Militar } \\
\text { Central, Caba, } \\
\text { Buenos Aires, } \\
\text { Argentina }\end{array}$ & $\begin{array}{l}\text { Prevention of Severe } \\
\text { Covid-19 in Infected } \\
\text { Elderly by Early } \\
\text { Administration of } \\
\text { Convalescent Plasma } \\
\text { With High-titers of } \\
\text { Antibody Against SARS- } \\
\text { CoV2 } \\
\end{array}$ & No hallado & Reclutamiento & $\begin{array}{l}\text { Pacientes } \\
\text { hospitalizados de } \\
65 \text { años o más con } \\
\text { COVID-19 }\end{array}$ & $\begin{array}{l}250 \mathrm{ml} \text { de plasma convaleciente con } \\
\text { título de IgG contra el SARS CoV-2/ } \\
\text { Comparador de placebo }\end{array}$ & $\begin{array}{l}\text { Desarrollo de } \\
\text { enfermedad } \\
\text { respiratoria grave } \\
\text { después de } 12 \text { horas } \\
\text { de la infusión hasta } \\
\text { el día15 después de } \\
\text { la infusión }\end{array}$ \\
\hline NCT04468009 & $\begin{array}{l}\text { Hospital Francisco } \\
\text { Javier Muñiz, } \\
\text { Ciudad Autonoma } \\
\text { de Buenos Aire, } \\
\text { Argentina }\end{array}$ & $\begin{array}{l}\text { Treatment of Critically III } \\
\text { Patients With Covid-19 } \\
\text { With Convalescent } \\
\text { Plasma }\end{array}$ & Fase 2 & Reclutamiento & $\begin{array}{l}\text { Pacientes } \\
\text { hospitalizados } \\
\text { críticos con COVID- } \\
19\end{array}$ & $\begin{array}{l}\text { PCC-19 } \\
\text { Tratamiento con plasma de } \\
\text { convalecencia / Cuidado estándar }\end{array}$ & $\begin{array}{l}\text { Mortalidad a los } 30 \\
\text { días de ingreso a la } \\
\text { Unidad de Cuidados } \\
\text { Intensivos (UCI) }\end{array}$ \\
\hline NCT04452812 & $\begin{array}{l}\text { Hospital } \\
\text { Universitario "Dr. } \\
\text { Gonzalo Valdés } \\
\text { Valdés", Saltillo, } \\
\text { Coahuila, Mexico }\end{array}$ & $\begin{array}{l}\text { Statistical and } \\
\text { Epidemiological Study } \\
\text { Based on the Use of } \\
\text { Convalescent Plasma for } \\
\text { the Management of } \\
\text { Patients With COVID-19 } \\
\end{array}$ & Fase 2 & $\begin{array}{l}\text { Aún no se ha } \\
\text { reclutado }\end{array}$ & $\begin{array}{l}\text { Pacientes } \\
\text { hospitalizados con } \\
\text { COVID-19. } \\
\text { Pacientes con } \\
\text { neumonía }\end{array}$ & $\begin{array}{l}\text { El plasma se dividirá en alícuotas de } \\
200 \mathrm{ml} \text { para su almacenamiento a - } 60 \\
{ }^{\circ} \mathrm{C} \text { hasta su uso. Se administrará en } 2 \\
\text { dosis separadas de } 200 \mathrm{ml} \text { en un } \\
\text { intervalo de } 12 \text { horas/ No control }\end{array}$ & $\begin{array}{l}\text { Mortalidad durante } \\
\text { los primeros } 30 \text { días } \\
\text { de tratamiento }\end{array}$ \\
\hline NCT04425837 & $\begin{array}{l}\text { Fundación Santa } \\
\text { Fe de Bogotá, } \\
\text { Bogotá, } \\
\text { Cundinamarca, } \\
\text { Colombia }\end{array}$ & $\begin{array}{l}\text { Effectiveness and Safety } \\
\text { of Convalescent Plasma } \\
\text { in Patients With High- } \\
\text { risk COVID-19 }\end{array}$ & Fase 3 & $\begin{array}{l}\text { Aún no se ha } \\
\text { reclutado }\end{array}$ & $\begin{array}{l}\text { Pacientes } \\
\text { hospitalizados con } \\
\text { COVID-19 de alto } \\
\text { riesgo }\end{array}$ & $\begin{array}{l}\text { Transfusión de plasma de pacientes } \\
\text { convalecientes de COVID-19 con RT-PCR } \\
\text { negativa, y títulos de anticuerpos de 1: } \\
160 \text { o más a una dosis de } 400 \mathrm{ml} \\
\text { distribuida en dos dosis administradas } \\
\text { el mismo día por vía intravenosa / } \\
\text { Cuidado estándar }\end{array}$ & $\begin{array}{l}\text { Mortalidad a los } 30 \\
\text { días }\end{array}$ \\
\hline
\end{tabular}

Continúa... 
... viene de la tabla anterior

\begin{tabular}{|c|c|c|c|c|c|c|c|}
\hline Registro & Lugar/Sede & Título & $\begin{array}{c}\text { Fase del } \\
\text { ensayo }\end{array}$ & Estado & $\begin{array}{l}\text { Características de los } \\
\text { pacientes }\end{array}$ & Intervención/Control & Desenlace primario \\
\hline NCT04415086 & $\begin{array}{l}\text { University of Sao } \\
\text { Paulo - General } \\
\text { Hospital, São } \\
\text { Paulo, SP, Brazil }\end{array}$ & $\begin{array}{l}\text { Treatment of Patients } \\
\text { With COVID-19 With } \\
\text { Convalescent Plasma }\end{array}$ & Fase 2 & Reclutamiento & $\begin{array}{l}\text { Pacientes } \\
\text { hospitalizados, con } \\
\text { enfermedad grave } \\
\text { por COVID-19 }\end{array}$ & $\begin{array}{l}\text { Los pacientes en } 3 \text { grupos de } \\
\text { tratamiento: estándar A ; B en un } \\
\text { volumen de } 200 \mathrm{ml}(150-300 \mathrm{ml}) ; C \text { en un } \\
\text { volumen de } 400 \mathrm{ml}(300-600 \mathrm{ml}) \\
\text { /Tratamiento estándar }\end{array}$ & $\begin{array}{l}\text { Mejora clínica a los } \\
28 \text { días }\end{array}$ \\
\hline NCT04405310 & $\begin{array}{l}\text { Hospital Nava de } \\
\text { Alta Especialidad, } \\
\text { Mexico City, } \\
\text { Mexico; Hospital } \\
\text { General de Mexico } \\
\text { Dr Eduardo } \\
\text { Liceaga, Mexico } \\
\text { City, Mexico }\end{array}$ & $\begin{array}{l}\text { Convalescent Plasma of } \\
\text { Covid-19 to Treat SARS- } \\
\text { COV- } 2 \text { a Randomized } \\
\text { Doble Blind } 2 \text { Center Trial } \\
\text { (CPC-SARS) }\end{array}$ & Fase 2 & Reclutamiento & $\begin{array}{l}\text { Pacientes } \\
\text { hospitalizados con } \\
\text { COVID-19 en } \\
\text { estadío II y III de la } \\
\text { enfermedad. } \\
\text { Pacientes con } \\
\text { neumonía }\end{array}$ & $\begin{array}{l}\text { El volumen plasmático máximo } \\
\text { extraído por sesión no debe exceder los } \\
600 \mathrm{ml} \text {, excluyendo el volumen de } \\
\text { anticoagulante, o el } 16 \% \text { del volumen } \\
\text { sanguíneo total, en ausencia de } \\
\text { reemplazo volumétrico / Placebo } \\
\text { (hartmann más albumina) }\end{array}$ & $\begin{array}{l}\text { Mortalidad a los } 15 \\
\text { días }\end{array}$ \\
\hline NCT04395170 & $\begin{array}{l}\text { LifeFactors Zona } \\
\text { Franca SAS, } \\
\text { Medellín, } \\
\text { Antioquia, } \\
\text { Colombia }\end{array}$ & $\begin{array}{l}\text { Convalescent Plasma } \\
\text { (PC) and Human } \\
\text { Intravenous Anti-COVID- } \\
19 \text { Immunoglobulin (IV } \\
\text { Anti COVID-19 IgG) in } \\
\text { Patients Hospitalized for } \\
\text { COVID-19. }\end{array}$ & Fase 3 & $\begin{array}{l}\text { Aún no se ha } \\
\text { reclutado }\end{array}$ & $\begin{array}{l}\text { Pacientes } \\
\text { hospitalizados con } \\
\text { COVID-19 en } \\
\text { estadío I de la } \\
\text { enfermedad }\end{array}$ & $\begin{array}{l}\text { Esquema de dos dosis de } 200 \text { - } 250 \mathrm{ml} \\
\text { administradas los días } 1 \text { y } 3 \text { de la } \\
\text { intervención por vía intravenosa a una } \\
\text { dosis de solución de lgG al } 10 \% \\
\text { /Tratamiento estándar }\end{array}$ & $\begin{array}{l}\text { Ingreso a la UCI con } \\
\text { requerimiento de } \\
\text { ventilación mecánica } \\
\text { por } 1 \text { año }\end{array}$ \\
\hline NCT04391101 & $\begin{array}{l}\text { Hospital San } \\
\text { Vicente Fundacion, } \\
\text { Medellín, } \\
\text { Antioquia, } \\
\text { Colombia }\end{array}$ & $\begin{array}{l}\text { Convalescent Plasma for } \\
\text { the Treatment of Severe } \\
\text { SARS-CoV-2 (COVID-19) }\end{array}$ & Fase 3 & $\begin{array}{l}\text { Aún no se ha } \\
\text { reclutado }\end{array}$ & $\begin{array}{l}\text { Pacientes con } \\
\text { COVID-19 tratados } \\
\text { en UCl }\end{array}$ & $\begin{array}{l}\text { Administración de dos unidades de } \\
\text { plasma fresco congelado (entre } 400 \text { y } \\
500 \mathrm{ml} \text { ) obtenido de pacientes } \\
\text { convalecientes por infección por SARS- } \\
\text { CoV-2/ tratamiento de apoyo en UCl }\end{array}$ & $\begin{array}{l}\text { Mortalidad } \\
\text { intrahospitalaria } \\
\text { hasta } 28 \text { días. }\end{array}$ \\
\hline NCT04388410 & $\begin{array}{l}\text { Instituto Nacional } \\
\text { de Ciencias } \\
\text { Medicas y } \\
\text { Nutricion Salvador } \\
\text { Zubiran, Mexico } \\
\text { City, Tlalpan, } \\
\text { Mexico } \\
\end{array}$ & $\begin{array}{l}\text { Safety and Efficacy of } \\
\text { Convalescent Plasma } \\
\text { Transfusion for Patients } \\
\text { With COVID-19 }\end{array}$ & Fase 3 & Reclutamiento & $\begin{array}{l}410 \text { pacientes con } \\
\text { COVID } 19\end{array}$ & $\begin{array}{l}\text { Administrarán dos infusiones de } 200 \mathrm{ml} \\
\text { con un intervalo de } 24 \text { a } 72 \text { horas/ } \\
\text { Comparador de placebo: solución salina } \\
\text { normal }\end{array}$ & $\begin{array}{l}\text { Severidad y muerte a } \\
\text { los } 28 \text { dias }\end{array}$ \\
\hline NCT04385186 & $\begin{array}{l}\text { Clínica Antioquía, } \\
\text { Medellín, } \\
\text { Antioquía, } \\
\text { Colombia }\end{array}$ & $\begin{array}{l}\text { Inactivated Convalescent } \\
\text { Plasma as a Therapeutic } \\
\text { Alternative in Patients } \\
\text { CoViD-19 }\end{array}$ & Fase 2 & $\begin{array}{l}\text { Aún no se ha } \\
\text { reclutado }\end{array}$ & $\begin{array}{l}\text { Pacientes CoViD-19 } \\
\text { hospitalizados en } \\
\text { cualquiera de las } \\
\text { clínicas } \\
\text { participantes }\end{array}$ & $\begin{array}{l}\text { Día 0: Transfusión de } 200 \mathrm{~mL} \text { de plasma } \\
\text { convaleciente inactivado compatible } \\
\text { ABO -Rh Día 1: Transfusión de } 200 \mathrm{ml} \\
\text { de plasma convaleciente inactivado } \\
\text { compatible con ABO - Rh / tratamiento } \\
\text { de apoyo }\end{array}$ & $\begin{array}{l}\text { Reducción de la } \\
\text { mortalidad a los } 28 \\
\text { dias }\end{array}$ \\
\hline NCT04383535 & $\begin{array}{l}\text { Hospital Italiano } \\
\text { de Buenos Aires, } \\
\text { Ciudad Autonoma } \\
\text { de Buenos Aire, } \\
\text { Ciudad Autonoma } \\
\text { De Buenos Aires, } \\
\text { Argentina }\end{array}$ & $\begin{array}{l}\text { Convalescent Plasma and } \\
\text { Placebo for the } \\
\text { Treatment of COVID-19 } \\
\text { Severe Pneumonia }\end{array}$ & No hallado & Completado & $\begin{array}{l}\text { Pacientes con } \\
\text { neumonía por Covid- } \\
19 \text { y los criterios de } \\
\text { gravedad. }\end{array}$ & $\begin{array}{l}\text { Se administra un volumen a } \\
\text { transfundir será de } 10 \text { a } 15 \mathrm{ml} / \mathrm{kg} \\
\text { ajustando el volumen al peso / } \\
\text { Atención estandar }\end{array}$ & $\begin{array}{l}\text { Estado clínico } \\
\text { durante el } \\
\text { seguimiento a los } 30 \\
\text { día }\end{array}$ \\
\hline NCT04381858 & $\begin{array}{l}\text { Centenario } \\
\text { Hospital Miguel } \\
\text { Hidalgo, } \\
\text { Aguascalientes, } \\
\text { Mexico }\end{array}$ & $\begin{array}{l}\text { Convalescent Plasma vs } \\
\text { Human Immunoglobulin } \\
\text { to Treat COVID-19 } \\
\text { Pneumonia }\end{array}$ & Fase 3 & Reclutamiento & $\begin{array}{l}\text { Pacientes } \\
\text { hospitalizas con } \\
\text { prueba RT-qPCR } \\
\text { SARS-CoV-2 } \\
\text { positiva o TC } \\
\text { compatible con un } \\
\text { diagnóstico de } \\
\text { neumonía COVID-19 }\end{array}$ & $\begin{array}{l}\text { Infusión de } 400 \mathrm{ml} \text { ( } 2 \text { unidades) de } \\
\text { plasma/ No control }\end{array}$ & $\begin{array}{l}\text { Tiempo medio con } \\
\text { ventilación mecánica } \\
\text { invasiva, } 3 \text { meses }\end{array}$ \\
\hline NCT04375098 & $\begin{array}{l}\text { Hospital Clínico } \\
\text { Universidad } \\
\text { Católica, Santiago, } \\
\text { Chile }\end{array}$ & $\begin{array}{l}\text { Efficacy and Safety of } \\
\text { Early COVID-19 } \\
\text { Convalescent Plasma in } \\
\text { Patients Admitted for } \\
\text { COVID-19 Infection }\end{array}$ & Fase 2 & Completado & $\begin{array}{l}\text { Pacientes con alto } \\
\text { riesgo de } \\
\text { insuficiencia } \\
\text { respiratoria } \\
\text { asociada a COVID19 }\end{array}$ & $\begin{array}{l}\text { Plasma de convalecencia COVID-19, } 200 \\
\mathrm{ml} \text { los días } 1 \text { y } 2 \text { al ingreso/No control }\end{array}$ & $\begin{array}{l}\text { Ventilacion } \\
\text { Mecanica,hospitaliza } \\
\text { ción de más de } 14 \\
\text { días o muerte } \\
\text { durante la } \\
\text { hospitalización, } \\
\text { seguimiento } 1 \text { mes. }\end{array}$ \\
\hline NCT04357106 & $\begin{array}{l}\text { Centro de } \\
\text { Hematología y } \\
\text { Medicina Interna, } \\
\text { Puebla, Mexico }\end{array}$ & $\begin{array}{l}\text { COPLA Study: Treatment } \\
\text { of Severe Forms of } \\
\text { COronavirus Infection } \\
\text { With Convalescent } \\
\text { PLAsma }\end{array}$ & Fase 2 & Reclutamiento & $\begin{array}{l}\text { Pacientes con } \\
\text { formas graves de } \\
\text { COVID-19 }\end{array}$ & $\begin{array}{l}\text { Plasma de convalecencia obtenido por } \\
\text { aféresis } 200 \mathrm{ml} / \text { no control }\end{array}$ & $\begin{array}{l}\text { Lesión pulmonar a } \\
\text { los } 7 \text { dias, } \\
\text { supervivencia } \\
\text { general de } 15 \text { a } 30 \\
\text { dias. }\end{array}$ \\
\hline
\end{tabular}

Continúa... 
... viene de la tabla anterior

\begin{tabular}{|c|c|c|c|c|c|c|c|}
\hline Registro & Lugar/Sede & Título & $\begin{array}{c}\text { Fase del } \\
\text { ensayo }\end{array}$ & Estado & $\begin{array}{c}\text { Características de los } \\
\text { pacientes }\end{array}$ & Intervención/Control & Desenlace primario \\
\hline NCT04356482 & $\begin{array}{l}\text { Hospital Del Issste } \\
\text { Regional En } \\
\text { Guadalajara } \\
\text { Jalisco, } \\
\text { Guadalajara, } \\
\text { Jalisco, Mexico }\end{array}$ & $\begin{array}{l}\text { CONVALESCENT PLASMA } \\
\text { FOR ILL PATIENTS BY } \\
\text { COVID-19 }\end{array}$ & Fase 2 & Reclutamiento & $\begin{array}{l}\text { Pacientes graves y } \\
\text { muy graves por } \\
\text { COVID-19 } \\
\text { Hospitalizados }\end{array}$ & $\begin{array}{l}\text { Dosis por cada tipo de grupo de } \\
\text { pacientes / No control }\end{array}$ & $\begin{array}{l}\text { Mejoría clínica - } 1 \text { a } \\
\text { dia }+22\end{array}$ \\
\hline NCT04333355 & $\begin{array}{l}\text { Hospital San José, } \\
\text { Monterrey, Nuevo } \\
\text { Leon, Mexico }\end{array}$ & $\begin{array}{l}\text { Safety in Convalescent } \\
\text { Plasma Transfusion to } \\
\text { COVID-19 }\end{array}$ & Fase 1 & Reclutamiento & $\begin{array}{l}\text { Pacientes } \\
\text { críticamente } \\
\text { enfermos con } \\
\text { CovID-19 } \\
\end{array}$ & $\begin{array}{l}\text { El plasma se fraccionará en } 250 \mathrm{ml} \\
\text { /Atencion estandar }\end{array}$ & $\begin{array}{l}\text { Efectos secundarios } \\
\text { a los } 14 \text { dias }\end{array}$ \\
\hline NCT04332835 & $\begin{array}{l}\text { Universidad del } \\
\text { Rosario, Bogota, } \\
\text { Cundinamarca, } \\
\text { Colombia }\end{array}$ & $\begin{array}{l}\text { Convalescent Plasma for } \\
\text { Patients With COVID-19: } \\
\text { A Randomized, Single } \\
\text { Blinded, Parallel, } \\
\text { Controlled Clinical Study }\end{array}$ & Fase 3 & Reclutamiento & $\begin{array}{l}\text { Pacientes } \\
\text { hospitalizados con } \\
\text { CovID-19 }\end{array}$ & $\begin{array}{l}\text { Día 1: CP-COVID19, } 250 \text { mililitros. Día } \\
\text { 2: CP-COVID19, } 250 \text { mililitros/ Terapia } \\
\text { estandar }\end{array}$ & $\begin{array}{l}\text { Cambio en la carga } \\
\text { viral los días } 0,4,7, \\
14 \text { y } 28\end{array}$ \\
\hline NCT04332380 & $\begin{array}{l}\text { Universidad del } \\
\text { Rosario, Bogota, } \\
\text { Cundinamarca, } \\
\text { Colombia }\end{array}$ & $\begin{array}{l}\text { Convalescent Plasma for } \\
\text { Patients With COVID-19: } \\
\text { A Pilot Study (CP-COVID- } \\
\text { 19) }\end{array}$ & Fase 2 & Completado & $\begin{array}{l}\text { Pacientes } \\
\text { hospitalizados con } \\
\text { COVID-19 }\end{array}$ & $\begin{array}{l}\text { Día 1: CP-COVID19, } 250 \mathrm{ml} \text { Día 2: } \\
\text { CP-COVID19, } 250 \mathrm{ml} \text {./ No control }\end{array}$ & $\begin{array}{l}\text { Cambio en la carga } \\
\text { viral en los días } 0,4 \text {, } \\
7,14 \text { y } 28\end{array}$ \\
\hline RBR-4vm3yy & $\begin{array}{l}\text { Instituto Estatal de } \\
\text { Hematología } \\
\text { Arthur Siqueira } \\
\text { Cavalcanti, Rio de } \\
\text { Janeiro, Brasil }\end{array}$ & $\begin{array}{l}\text { Efecto del plasma } \\
\text { convaleciente en } \\
\text { pacientes críticamente } \\
\text { enfermos con COVID-19 } \\
\text { grave }\end{array}$ & Fase 1 & Reclutamiento & $\begin{array}{l}\text { Pacientes } \\
\text { hospitalizados con } \\
\text { enfermedad grave } \\
\text { por COVID-19 }\end{array}$ & $\begin{array}{l}\text { Se } \\
\text { incluirán } 20 \text { pacientes, Inmunización } \\
\text { pasiva /Controles históricos }\end{array}$ & $\begin{array}{l}\text { Mejoría durante la } \\
\text { estancia en la UCI los } \\
\text { primeros } 14 \text { días }\end{array}$ \\
\hline RBR-7jqpnw & $\begin{array}{l}\text { Complejo } \\
\text { Hospitalario } \\
\text { Universitario } \\
\text { Oswaldo Cruz y } \\
\text { Pronto Socorro } \\
\text { Cardiológico de } \\
\text { Pernambuco - } \\
\text { Universidad de } \\
\text { Pernambuco, } \\
\text { Recife, Brasil }\end{array}$ & $\begin{array}{l}\text { Efecto del plasma } \\
\text { convaleciente COVID-19 } \\
\text { producido por HEMOPE: } \\
\text { un estudio aleatorizado, } \\
\text { con un grupo } \\
\text { comparativo en varios } \\
\text { centros }\end{array}$ & Fase 3 & $\begin{array}{l}\text { Aún no se ha } \\
\text { reclutado }\end{array}$ & $\begin{array}{l}\text { Pacientes } \\
\text { hospitalizados } \\
\text { críticos con } \\
\text { diagnóstico de } \\
\text { COVID-19 }\end{array}$ & $\begin{array}{l}110 \text { participantes, Plasmaféresis / } \\
\text { Control estándar }\end{array}$ & $\begin{array}{l}\text { Reducción del } 50 \% \text { de } \\
\text { letalidad en el grupo } \\
\text { de intervención en } \\
\text { comparación con el } \\
\text { grupo de control }\end{array}$ \\
\hline
\end{tabular}

